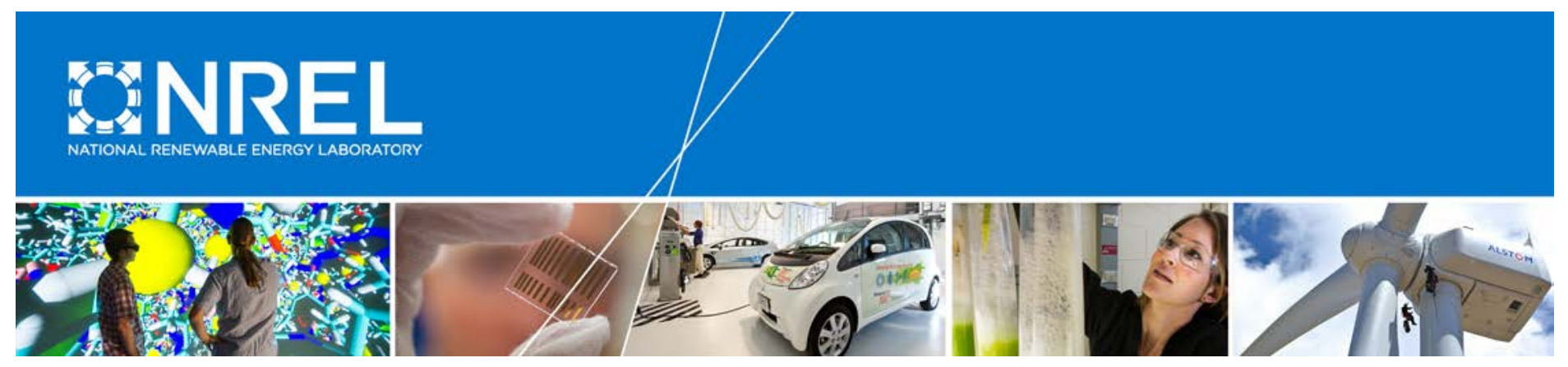

\title{
Position Paper: Hydrogen Spillover Limitations for Onboard Hydrogen Storage
}

Thomas Gennett

National Renewable Energy Laboratory

Prepared for the U.S. Department of Energy January 2015

NREL is a national laboratory of the U.S. Department of Energy Office of Energy Efficiency \& Renewable Energy Operated by the Alliance for Sustainable Energy, LLC

This report is available at no cost from the National Renewable Energy Laboratory (NREL) at www.nrel.gov/publications.

Milestone Report

NREL/TP-5900-71113

January 2015

Contract No. DE-AC36-08G028308 


\section{Position Paper: Hydrogen Spillover Limitations for Onboard Hydrogen Storage}

Thomas Gennett

National Renewable Energy Laboratory

Prepared for the U.S. Department of Energy January 2015

\section{Suggested Citation}

Gennett, Thomas. 2015. Position Paper: Hydrogen Spillover Limitations for Onboard Hydrogen Storage. Golden, CO: National Renewable Energy Laboratory. NREL/TP-5900-71113.
National Renewable Energy Laboratory 15013 Denver West Parkway

Golden, CO 80401

303-275-3000 • www.nrel.gov
NREL is a national laboratory of the U.S. Department of Energy Office of Energy Efficiency \& Renewable Energy Operated by the Alliance for Sustainable Energy, LLC

This report is available at no cost from the National Renewable Energy Laboratory (NREL) at www.nrel.gov/publications.

Contract No. DE-AC36-08GO28308 


\section{NOTICE}

This work was authored by the National Renewable Energy Laboratory, operated by Alliance for Sustainable Energy, LLC, for the U.S. Department of Energy (DOE) under Contract No. DE-AC36-08GO28308. Funding provided by the U.S. Department of Energy Office of Energy Efficiency and Renewable Energy Fuel Cell Technologies Office. The views expressed herein do not necessarily represent the views of the DOE or the U.S. Government.

This report is available at no cost from the National Renewable Energy Laboratory (NREL) at www.nrel.gov/publications.

U.S. Department of Energy (DOE) reports produced after 1991 and a growing number of pre-1991 documents are available free via www.OSTI.gov.

Cover Photos by Dennis Schroeder: (left to right) NREL 26173, NREL 18302, NREL 19758, NREL 29642, NREL 19795.

NREL prints on paper that contains recycled content. 


\section{Hydrogen Spillover Limitations for Onboard Hydrogen Storage}

The U.S. Department of Energy Office of Energy Efficiency and Renewable Energy (DOE EERE) Hydrogen Storage sponsored research projects are focused on the development of hydrogen storage systems that meet or exceed the DOE's goals for the onboard hydrogen storage in hydrogen-powered vehicles. Recently there has been a tremendous interest and controversy concerned with the disparity of results associated with weak chemisorption, i.e., spillover, materials for hydrogen storage. The National Renewable Energy Laboratory (NREL) and DOE dedicated considerable resources over the last few years to develop/perform the requisite measurements in order to establish the validity, capacity, kinetics, and overall performance of these materials.

'Hydrogen spillover' is a well-known phenomenon in catalysis, involving the dissociative chemisorption of hydrogen molecules on metal nanoparticles, followed by the migration of atomic hydrogen onto a support. In hydrogen storage applications, this storage enhancement mechanism has been investigated in detail most notably via the noble metal decoration of high surface area $\left(>2,500 \mathrm{~m}^{2} / \mathrm{g}\right)$ carbon-based supports. ${ }^{1-8}$ Overall, the observations of hydrogen storage that can be attributed to a spillover-type effect vary widely, from a several-fold enhancement to a negligible effect within the experimental uncertainty. ${ }^{9}$ In part, this wide variation may be caused by micro-structural changes resulting from the metal doping, such as reduced pore volume and specific surface area. A significant result of the extensive DOE-NREL efforts was the first reported spectroscopic (DRIFTS and Neutron Scattering) evidence of "spiltover" hydrogen atoms onto a carbon surface. Disappointingly, however, it was only observed with modest $(<15 \%)$ enhancements of sorption resulting in total capacities considerably less than the 2020 DOE targets. While larger enhancements up to 50\% were observed for low hydrogen capacity materials, this was found to be primarily caused by the reduction of the metal centers and the formation of water. After multiple hydrogen sorption cycles and once the metal was reduced, the observed enhancement was considerably less $(<15 \%)$. Overall, the spillover mechanism onto carbon-based sorbents is not yet fully understood and still under considerable debate $^{9-15}$ due to the absence of consistent empirical results and a fundamental microscopic picture.

It is important to note however, that as interest in the hydrogen storage spillover process peaked in the early part of this decade, a considerable amount of new information has come to light regarding the intrinsic problems that could complicate the interpretation of empirical results, beyond systematic instrumentation errors. The following list provides examples of the items most often reported: (1) hydrogenation reactions can occur if the metal nanoparticles are in a fully or partially oxidized state; ${ }^{16}$ (2) residual organics may occlude the noble metal deposition precursor from accessing deep into the pores, and these precursors can undergo catalytic reduction reactions (which would appear as an erroneous hydrogen sorption) for multiple hydrogen sorption/desorption cycles; ${ }^{17}$ (3) a variation of $\mathrm{H}_{2}$ interaction properties at unsaturated atomic sites inside carbon support could lead to irreversible side reactions such as the hydrogenation of the carbon ( $\mathrm{C}-\mathrm{H}$ bonds) and oxygen $(\mathrm{O}-\mathrm{H})$ sites being the most obvious; ${ }^{10,12}$ (4) the variation of substituents that populate the pore structure in very high surface area carbon 
materials can lead to multiple side reactions; (5) theory which predicts the existence of thermodynamic energy valleys resulting in water formation (which also would appear as an erroneous hydrogen sorption); ${ }^{18-20}$ and most recently (6) results indicating that catalytic activity of the metal certainly can enhance adsorption kinetics, but with significant irreversible sorption hysteresis attributed to irreversible chemical hydrogenation of the substrate. ${ }^{21-22}$

Therefore, even though there are validated results in the literature that the hydrogen spillover process may result in an observed $10 \%$ to $50 \%$ increase in hydrogen sorption capacities, it has only been verified for well-defined, low surface area materials with inherently low $(<0.5 \mathrm{wt} . \%$ $\mathrm{H}_{2}$ ) gravimetric capacity - and even in these cases after 2-3 cycles the enhancement is greatly reduced. Thus, although there is now definitive spectroscopic evidence in the literature (DRIFTS, NMR, RAMAN, Neutron Scattering) of studies that confirm reversible hydrogen adsorption/desorption spillover behavior, these confirmations have only been observed for materials with low initial hydrogen capacity.

In a recent paper, ${ }^{23}$ we address the above issue through systematic density-functional-theory calculations. Unlike the conventional experimental study of $\mathrm{H}$ chemisorption using an atomic $\mathrm{H}$ source, hydrogen storage studies use molecular hydrogen sources; therefore, the chemisorption state must be in a much lower energy level. In order to lower the total energy, each chemisorbed $\mathrm{H}$ atom must be paired up with another $\mathrm{H}$ atom on the opposite side of the graphene sheet. The two $\mathrm{H}$ atoms in a pair are strongly correlated and must move cooperatively. In this situation, recombination of $\mathrm{H}$ atoms on the same side is mostly suppressed because each recombination breaks two $\mathrm{H}$ pairs and is energetically very unfavorable. Surprisingly, we found that $\mathrm{H}$ migration can actually happen at room temperature through a cooperative motion of $\mathrm{H}$ pairs when mediated by water molecules. This study is important for both hydrogen storage technology and organic chemistry in terms of $\mathrm{C}-\mathrm{H}$ bond activation.

If one assumes that hexagonal patches form and grow simultaneously surrounding a catalytic particle, then ideally, six such patches with a size similar to the catalytic particle roughly fills the $360^{\circ}$ angular space, which terminates the spillover around that catalytic particle. That gives a maximum area ratio of $6: 1$ of $\mathrm{H}$ covered graphene over that of metal covered graphene. Based on this ratio, the lattice parameters, standard atomic weights (12.011 for C, 106.45 for $\mathrm{Pd}$ ), a homogeneous distribution of Pd nanoparticles ( 3 atomic layer thickness, $2 \mathrm{~nm}$ diameter) on graphene, and an optimum inter-particle distance of 5-6 nm, the maximum $\mathrm{H}$ capacity is derived as $2.5-3.0 \mathrm{wt} . \%$.

Overall, the primary thermodynamic paradox of how a reversible hydrogenation reaction can occur at room temperature with the formation of a mobile $30 \mathrm{~kJ} / \mathrm{mol} \mathrm{C}-\mathrm{H}$ bond has not been adequately addressed. However, as shown in the recent paper by Zhao et al., once the known region of influence of the metal center is calculated, along with the metal added to the material in the optimal spacing that would allow for $100 \%$ hydrogenation of the carbon surface, the maximum theoretical capacity would only be $2.75+/-0.5 \% \mathrm{w} / \mathrm{w}$. Spillover is an interesting scientific phenomena; however, the current use of $2 \mathrm{~nm}$ metal particles to mediate the sorption of hydrogen onto a sorbent is not viable for application to transportation applications. So while the investigation of hydrogen sorption via a spillover process is of considerable interest, at this time it is still, at a scientific level, at too early of a research and development stage to be considered as a viable alternative to other more well-developed hydrogen storage technologies. However, this 
is not to say that research in this area is not important. Fundamental research, such as work sponsored by the Office of Basic Energy Sciences or the National Science Foundation, where the mechanism could be established in great detail in order to better define substrate chemistries as well as the nano- and meso-scale structures needed to optimize materials suitable for incorporation with the spillover mechanism could be beneficial.

In summary, hydrogen sorption via a spillover process is not considered a viable pathway to achieve the 2020 DOE metrics as a hydrogen sorption material for transportation applications. 


\section{Acknowledgements}

This work was fully supported by the U.S. Department of Energy under Contract No. DE-AC3608GO28308 with Alliance for Sustainable Energy, LLC, the Manager and Operator of the National Renewable Energy Laboratory. Funding provided by the U.S. Department of Energy, Office of Energy Efficiency and Renewable Energy, Fuel Cell Technologies Office. The views and opinions of the authors expressed herein do not necessarily state or reflect those of the United States Government or any agency thereof. Neither the United States Government nor any agency thereof, nor any of their employees, makes any warranty, expressed or implied, or assumes any legal liability or responsibility for the accuracy, completeness, or usefulness of any information, apparatus, product, or process disclosed, or represents that its use would not infringe privately owned rights. 


\section{References}

1. H. Chen and R. T. Yang, "Catalytic effects of TiF3 on hydrogen spillover on Pt/carbon for hydrogen storage," Langmuir 26, no. 19 (2010): 15394-98.

2. A. J. Lachawiec, Jr., G. Qi, and R. T. Yang, "Hydrogen storage in nanostructured carbons by spillover: bridge-building enhancement," Langmuir 21, no. 24 (2005): 11418-24.

3. A. J. Lachawiec, Jr. and R. T. Yang, "Isotope tracer study of hydrogen spillover on carbonbased adsorbents for hydrogen storage," Langmuir 24, no. 12 (2008): 6159-65.

4. Y. Li and R. T. Yang, "Hydrogen storage in metal-organic frameworks by bridged hydrogen spillover," J. Am. Chem. Soc. 128, no. 25 (2006): 8136-37.

5. Y. Li and R. T. Yang, "Significantly enhanced hydrogen storage in metal-organic frameworks via spillover," J. Am. Chem. Soc. 128, no. 3 (2006): 726-27.

6. N. R. Stuckert, L. Wang, and R. T. Yang, "Characteristics of hydrogen storage by spillover on Pt-doped carbon and catalyst-bridged metal organic framework," Langmuir 26, no. 14 (2010): 11963-71.

7. F. H. Yang, A. J. Lachawiec, Jr., and R. T. Yang, "Adsorption of spillover hydrogen atoms on single-wall carbon nanotubes," J. Phys. Chem. B 110, no. 12 (2006): 6236-44.

8. R. T. Yang and Y. Wang, "Catalyzed hydrogen spillover for hydrogen storage," J. Am. Chem. Soc. 131, no. 12 (2009): 4224-26.

9. N. P. Stadie, J. J. Purewal, C. C. Ahn, and B. Fultz, "Measurements of Hydrogen Spillover in Platinum Doped Superactivated Carbon," Langmuir 26, no. 19 (2010): 15481-85.

10. A. Ansón, E. Lafuente, E. Urriolabeitia, R. Navarro, A. M. Benito, W. K. Maser, and M. T. Martínez, "Hydrogen Capacity of Palladium-Loaded Carbon Materials." J. Phys. Chem. B 110, no. 13 (2006): 6643-48.

11. R. Campesi, F. Cuevas, R. Gadiou, E. Leroy, M. Hirscher, C. Vix-Guterl, M. Latroche, "Hydrogen storage properties of Pd nanoparticle/carbon template composites," Carbon 46, no. 2 (2008): 206-14.

12. C. I. Contescu, C. M. Brown, Y. Liu, V. V. Bhat, and N. C. Gallego, "Detection of Hydrogen Spillover in Palladium-Modified Activated Carbon Fibers during Hydrogen Adsorption," $J$. Phys. Chem. C 113, no. 14 (2009): 5886-90.

13. M. Hirscher, "Remarks about spillover and hydrogen adsorption - Comments on the contributions of AV Talyzin and RT Yang," Micropor. Mesopor. Mat. 135, no. 1-3 (2010), 209-10.

14. A. V. Talyzin and S. M. Luzan, "Hydrogen adsorption in Pt catalyst/MOF-5 materials," Micropor. Mesopor. Mat. 135, no. 1-3 (2010): 201-05. 
15. S. M. Luzan and A. V. Talyzin, "Comment to the "Response to "Hydrogen adsorption in Pt catalyst/MOF-5 materials"” by Li et al.," Micropor. Mesopor. Mat. 139, no. 1-3 (2011): 21618.

16. C. M. Ghimbeu, C. Zlotea, R. Gadiou, F. Cuevas, E. Leroy, M. Latroche, and C. Vix-Guterl, "Understanding the mechanism of hydrogen uptake at low pressure in carbon/palladium nanostructured composites," J. Mater. Chem. 21, no. 44 (2011): 17765-75.

17. S. B. Kalidindi, H. Oh, M. Hirscher, D. Esken, C. Wiktor, S. Turner, G. Van Tendeloo, and R. A. Fischer, "Metal@COFs: Covalent Organic Frameworks as Templates for Pd Nanoparticles and Hydrogen Storage Properties of Pd@COF-102 Hybrid Material," Chemistry-A European Journal 18, no. 35 (2012): 10848-56.

18. G. Mpourmpakis, E. Tylianakis, and G. E. Froudakis, "Carbon nanoscrolls: a promising material for hydrogen storage," Nano. Lett. 7, no. 7 (2007): 1893-97.

19. G. M. Psofogiannakis and G. E. Froudakis, "DFT study of hydrogen storage by spillover on graphite with oxygen surface groups," J. Am. Chem. Soc. 131, no. 42 (2009): 15133-35.

20. G. M. Psofogiannakis and G. E. Froudakis, "Fundamental studies and perceptions on the spillover mechanism for hydrogen storage," Chem. Commun. (Camb) 47, no. 28 (2011): 7933-43.

21. R. Campesi, F. Cuevas, M. Latroche, and M. Hirscher, "Hydrogen spillover measurements of unbridged and bridged metal-organic frameworks_-revisited," Phys. Chem. Chem. Phys. 12, no. 35 (2010): 10457-59.

22. H. Oh, T. Gennett, P. Atanassov, M. Kurttepeli, S. Bals, K. E. Hurst, and M. Hirscher, "Hydrogen adsorption properties of platinum decorated hierarchically structured templated carbons," Micropor. Mesopor. Mat. 177 (2013): 66-74.

23. Y. Zhao and T. Gennett, "Water-mediated cooperative migration of chemisorbed hydrogen on graphene," Phys. Rev. Lett. 112, no. 7 (2014): 076101. 